\title{
Leitura de Acolhimento: Uma Experiência de Devir Consciente
}

\author{
Receptive Reading: An Experience of Becoming Aware
}

\author{
Maria do Carmo Carvalho Cabral* \& Virgínia Kastrup \\ Universidade Federal do Rio de Janeiro
}

\begin{abstract}
Resumo
O trabalho discute os efeitos de uma experiência de leitura silenciosa e solitária, de textos literários, sobre o leitor. Parte da noção de cognição ampliada, conforme comparece na abordagem da enação de Varela, e do conceito de cognição inventiva de Kastrup, e propõe a leitura como uma experiência de devir consciente. Recorre ainda às idéias de Chartier, sobre as práticas de leitura e de Larrosa quanto ao caráter transformador da leitura. Desenvolve a noção de que a leitura de literatura propicia um encontro consigo e com a alteridade, podendo propiciar uma abertura para o desconhecido e para a invenção de si.

Palavras-chave: Leitura; Literatura; Cognição; Invenção.
\end{abstract}

\begin{abstract}
This work discusses the experience of reading literature in silence and solitude, focusing its effects on the reader. The starting point is the enlargement of cognition as presented in Varela's enactive approach and the concept of inventive cognition as formulated by Kastrup. Then, it proposes the reading as an experience of becoming aware. The work is also based on Chartier's ideas about reading practices and uses the theory of Larrosa regarding the transformative aspect of reading as well. The idea that reading literature provides a meeting with otherness is developed. It may constitute an opening for the unknown and an opportunity of inventing oneself.

Keywords: Reading; Literature; Cognition; Invention.
\end{abstract}

"A leitura não é somente uma operação abstrata de intelecção; ela é engajamento do corpo, inscrição num espaço, relação consigo e com os outros" (Chartier, 1999, p. 16).

$\mathrm{Na}$ contemporaneidade percebe-se uma tendência, especialmente entre os jovens, de despender grande parte do tempo disponível em ambiente virtual ou cibernético, ficando muitas vezes a leitura reduzida ao âmbito da informação e da obrigatoriedade, na Internet, em jornais, revistas e livros didáticos. Em geral lê-se para manter-se informado, mas não se vivencia o prazer da leitura, não se permite que a leitura seja uma experiência plena.

A leitura é tema tradicional de pesquisa em diversas áreas do conhecimento. Um grande número de investigações em psicologia cognitiva privilegia o estudo das habilidades envolvidas na leitura. Partindo de uma concepção da cognição como representação, a leitura surge enquanto compreensão e decifração do texto escrito. Nes-

* Endereço para correspondência: Avenida Pasteur, 250, Urca, Rio de Janeiro, RJ, Brasil, CEP 22295-900. Tel.: (21) 3873 5328. E-mail: maria@sanz.com.br

Artigo derivado da tese de doutorado: "Encontros que nos movem: A leitura como experiência inventiva" defendida por Maria do Carmo Cabral em 2006, no Programa de PósGraduação em Psicologia da Universidade Federal do Rio de Janeiro (UFRJ), sob orientação da Profa. Dra. Virgínia Kastrup.

Agradecemos ao Conselho Nacional de Desenvolvimento Científico e Tecnológico (CNPq) pelo apoio concedido para a realização da tese. te panorama, surge a necessidade de se estudar o problema da leitura a partir de um novo enfoque, qual seja, o da cognição inventiva (Kastrup, 1999) e da abordagem da enação (Varela, Thompson, \& Rosch, 1991/2003). Não pretendendo propor um novo modelo para o entendimento de leitura, o objetivo deste artigo é experimentar idéias, fazer pensar e produzir movimento dentro deste tema. Para isso, procuramos realizar uma articulação entre idéias e conhecimentos de psicologia, ciências cognitivas e literatura.

A partir de uma revisão dos estudos sobre leitura no campo da psicologia cognitiva percebemos que a entrada mais freqüente diz respeito ao aprendizado da leitura ${ }^{1}$, traduzido, especialmente, em estudos acerca de suas habilidades e competências. De acordo com Ludovic Ferrand (2001) o estudo da leitura ocupa atualmente um lugar central no campo da psicologia cognitiva. As pesquisas nessa área buscam a compreensão da natureza e organização dos processos psicológicos implicados na leitura, desde a identificação das palavras até a compreensão dos textos. Utilizam, em geral, uma abordagem analítica, que procura

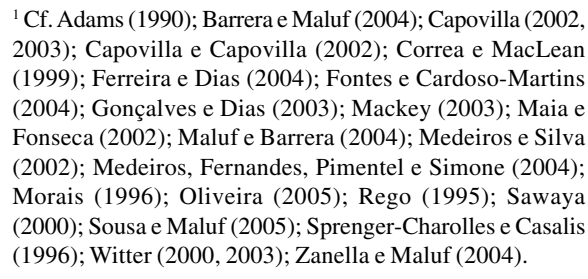

${ }^{1}$ Cf. Adams (1990); Barrera e Maluf (2004); Capovilla (2002, 2003); Capovilla e Capovilla (2002); Correa e MacLean (1999); Ferreira e Dias (2004); Fontes e Cardoso-Martins Fon), Gonçalves e Dias (2003), Mackey (2003), Maia e (2002); Medeiros, Fernandes, Pimentel e Simone (2004); Morais (1996); Oliveira (2005); Rego (1995); Sawaya (1996); Witter (2000, 2003); Zanella e Maluf (2004) 
decompor a atividade de leitura em seus elementos. Estes são, muitas vezes, examinados de forma estanque através de uma metodologia experimental, com tarefas construídas especificamente para sua investigação. As pesquisas em psicologia cognitiva buscam, em sua maioria, entender a atividade de leitura em termos dos eventos cerebrais, cognitivos, sensoriais e motores, visando principalmente a aplicação destes conhecimentos no processo de ensino e aprendizagem da leitura. É realizada ainda a monitoração da leitura por meio dos resultados e performances dos leitores. E, quando estes não correspondem ao esperado, a tendência é definir o tipo de dificuldade ou problema encontrado, para uma posterior indicação dos meios de intervenção a serem aplicados.

\section{Múltiplas Formas de Ler}

Livro

Tropeçavas nos astros desastrada

Quase não tínhamos livros em casa

E a cidade não tinha livraria

Mas os livros que em nossa vida entraram

São como a radiação de um corpo negro

Apontando pra expansão do Universo

Porque a frase, o conceito, o enredo, o verso

(E, sem dúvida, sobretudo o verso)

É o que pode lançar mundos no mundo . . .

(Caetano Veloso, 2004, p. 49).

Por outro lado, por ser uma prática cotidiana, todos pensam saber o que é ler. Muitos possuem uma crença, um conhecimento, sobre o que é a leitura. Assim, inicialmente parece necessário desnaturalizar tanto um saber do senso comum, quanto o paradigma dominante do processamento da informação. Nosso objetivo é recuperar em seu estudo seu caráter problemático e experiencial. Com este propósito, recorremos à abordagem histórica de Roger Chartier como forma de demonstrar a multiplicidade de práticas da leitura. Com seu trabalho fica claro que não existe "a leitura", mas diversas formas de ser leitor. E que o sentido do texto não está dado, pois sua construção ocorre na relação entre o leitor e a obra. Esta abordagem nos servirá de referência, juntamente com o trabalho de Jorge Larrosa (1996/ 2003), que trata a leitura do ponto de vista da diferença e da pluralidade.

Atualmente, quando pensamos em leitura, associamos a imagem de alguém solitário, lendo em silêncio um livro no formato como o conhecemos hoje - mesmo sem saber que esta forma tem o nome de códice. Roger Chartier, pesquisador da história do livro e da leitura, afirma: "Costurado, portátil, acessível, o livro do século XX é um possível companheiro de cada momento. Ele se tornou um objeto comum" (Chartier, 1998). O livro nos parece um objeto familiar. Ainda que não faça parte da vida de todos, uma boa parte das pessoas tem acesso ao livro quando chega à escola. E a leitura configura uma prática cotidiana para muitos. Mas não foi sempre assim. Chartier (1999) demonstra como o livro mudou ao longo do tempo e como as formas de composição e reprodução do escrito tiveram dife- rentes feições. E, principalmente, que a leitura não é simples identificação de letras e palavras e compreensão do texto. Seus estudos nos permitem perceber que a leitura não foi sempre feita da mesma forma ao longo do tempo nem em diferentes sociedades. E que, ainda hoje, não é sempre a mesma. A leitura não precisa ser somente uma leitura funcional, visando decifração de sentido. Existem outras dimensões a serem exploradas, com incontáveis maneiras de ler e de se apropriar do escrito.

A história da leitura vinha sendo tradicionalmente uma história do livro ou dos textos. Chartier, porém, marca a necessidade de se investigar as diferentes maneiras de ler, que são construídas por múltiplos fatores. Alguns dos aspectos que exercem influência sobre as práticas da leitura são fatores sócio-culturais dos leitores, tais como profissão, classe social, sexo, religião, escolaridade, etc. O tempo e o espaço, ou seja, a época histórica e o local onde elas se dão, também influenciam as formas de ler. Outros destes múltiplos fatores que contribuem para a diversidade das práticas de leitura são as habilidades de leitura, assim como as regras, hábitos, expectativas, objetivos e intenções de cada comunidade de leitores, além da própria forma material e das técnicas de reprodução do texto. Chartier explica que não se pode isolar o texto de sua materialidade, pois as formas materiais produzem efeitos em seus usos e apropriações. Todos estes fatores participam na construção dos mosaicos das diversas práticas da leitura.

Chartier (1995/2003) configura um amplo cenário histórico das práticas da leitura. Apontando diferenças em relação à modalidade física ou corporal do ato de ler, que pode ser realizado oralmente, em voz alta ou não, ou ser uma leitura visual e em silêncio. Em relação ao estilo de leitura, ela pode ser intensiva ou extensiva. Uma leitura intensiva é marcada pelo sagrado, restrita a poucos livros, que devem ser memorizados e recitados geração após geração. Na segunda metade do século XVIII este estilo de leitura dá lugar a um estilo extensivo, uma prática de leitura voraz, que não mais saboreia o texto, mas que o devora, para buscar o próximo livro o mais rápido possível. O sentido do sagrado, a repetição e o respeito pelos poucos textos disponíveis até então são deixados de lado e começa-se a exercer uma atividade mais crítica em relação ao que é lido em um volume muito maior. Quanto ao método de leitura, ele menciona o método monástico, religioso e o método escolástico, intelectual. Acerca dos efeitos da leitura, investiga práticas da leitura que trazem reconhecimento e outras leituras que são de descoberta. Há diferenças formais, relativas ao modo de transmissão do escrito, que pode se apresentar em volumen, códice e, mais recentemente, na tela do computador. E existem ainda diferenças técnicas ou tecnológicas, que se referem à reprodução dos textos e à maneira de se fazer o livro, como, por exemplo, um livro manuscrito (scribal culture) ou impresso (print culture).

Em resumo, podemos pensar essas diversas práticas da leitura apontadas por Chartier em relação a algumas questões principais: (a) $\mathrm{O}$ que ler: relativo às características 
formais e técnicas do texto - seu gênero, estilo, leitor ideal, protocolos de leitura -, e do livro - qual sua forma material e como foi feito; (b) Para que ler: onde se inserem as razões de ler, os objetivos, interesses e expectativas em relação à leitura; (c) Como ler: quanto às formas de leitura, que envolvem tanto a modalidade física do ato de ler e a capacidades do leitor, quanto o método, a forma e o ritmo de leitura e a relação entre o leitor e o texto; (d) Efeitos da leitura: o que vem com a leitura, o que ela traz - descoberta, reconhecimento, estranhamento, informação, alterização, prazer, fruição, problematização, fuga, distração, etc.

As práticas da leitura são constituídas, portanto, a partir de diversos fatores, como o livro e o texto, os lugares e épocas e os objetivos dos leitores, as formas de ler, tanto físicas quanto de acordo com as capacidades e possibilidades do leitor, e as relações que se estabelecem entre texto e leitor. A dicotomia entre alfabetizados e analfabetos, por exemplo, não é suficiente para dar conta da grande diversidade de posições frente ao escrito. Existem os que decifram as letras com dificuldade, mas que não conseguem compreender seu significado. Leitores que necessitam de uma leitura oralizada para entender o que estão lendo. Leitores mais lentos, outros mais rápidos. Leitores que visam apenas à aquisição de informação outros que lêem pela leitura em si. Existem diferentes formas de relação com o texto. Leituras receosas e distantes ou leituras mais abertas, onde há entrega e transformação. Uma experiência de leitura deste segundo tipo é relatada no livro No caminho de Swann. Proust nos fala de uma leitura onde o leitor vive as emoções das personagens, atingindo um estado interior onde a emoção é duplicada e que desencadeia no leitor venturas e desgraças que o modificam:

E uma vez que o romancista nos pôs nesse estado, no qual, como em todos os estados puramente interiores, cada emoção é duplicada, e em que o seu livro nos vai agitar como um sonho, mas um sonho mais claro do que aqueles que sonhamos ao dormir e cuja lembrança vai durar mais tempo, eis que então ele desencadeia em nós, durante uma hora, todas as venturas e todas as desgraças possíveis, algumas das quais levaríamos anos para conhecer na vida, e outras, as mais intensas dentre elas, jamais nos seriam reveladas . . (Proust, 1948/ 1956, p. 78).

\section{Uma Leitura de Acolhimento}

"Para ler bem é preciso ter todos os sentidos afiados, é preciso pôr tudo o que cada um é e é preciso ter aprendido a dançar. Mas faz falta também um certo temperamento, uma certa força vital” (Larrosa, 2002, p. 42).

Propomos tomar a leitura para além de uma capacidade de compreensão e de decifração de palavras e discutir sua dimensão de experiência e de abertura. Nossa ênfase recai na experiência do leitor, nos efeitos da leitura sobre a subjetividade. Tratamos aqui especificamente de uma leitura silenciosa, solitária de textos literários. Percebemos o con- tato com a literatura em sua dimensão estética, enquanto experiência transformadora, que envolve múltiplos aspectos, entre eles a produção da subjetividade, a invenção de si e do mundo, o encontro consigo e com a alteridade do texto, além da própria experiência estética de prazer e fruição do texto.

Pensando a partir da perspectiva do leitor, operamos uma diferenciação entre uma leitura de aquisição de informação e uma leitura de acolhimento ou à espreita. A primeira é uma prática segura e confortável, onde o leitor não se coloca em risco, mas pretende apenas reafirmar suas crenças e concepções de mundo, fazendo uma leitura autocentrada. Esta prática está ligada a uma concepção da cognição como representação, onde o leitor não se abre para que encontros aconteçam e busca somente adquirir conhecimentos. Desta forma, não é cogitado que ele venha a se transformar com a leitura. Mas há uma outra maneira de ler, característica de uma cognição inventiva, que nomeamos de leitura de acolhimento ou à espreita. Nesta, o leitor adota uma disposição aberta para acolher o que vem do texto. Estabelecendo uma relação intensa, de entrega, a leitura pode levar à criação de outras possibilidades de relação consigo, com o mundo e com a alteridade. O leitor se coloca em perigo e possibilita que ocorram transformações a partir do que leu e das ressonâncias que se deram nele.

Salientamos que esta é sempre uma possibilidade, mas não está garantida. A leitura não se dá sempre desta forma, nem a experiência é igual para todos. Para que uma leitura de acolhimento ocorra, diversos fatores são necessários, entre eles a própria alfabetização, e depois um outro tipo de aprendizado. Este depende da prática, é um cultivo, e visa alcançar uma atenção aberta (Depraz, Varela, \& Vermersch, 2003), de entrega e aceitação do que vem da leitura. Existe também uma questão de acaso e de sorte para que esses encontros aconteçam, não há garantia, mesmo para quem já teve essa experiência antes, mesmo quando lemos um autor que gostamos. Esta leitura exige um movimento de desprendimento de si, uma abertura para o desconhecido.

\section{Leitura e Devir Consciente}

A experiência, a possibilidade de que algo nos passe ou nos aconteça ou nos toque, requer um gesto de interrupção, um gesto que é quase impossível nos tempos que correm: requer parar para pensar, para olhar, parar para escutar, pensar mais devagar, olhar mais devagar e escutar mais devagar; parar para sentir, sentir mais devagar, demorar-se nos detalhes, suspender a opinião, suspender o juízo, suspender a vontade, suspender o automatismo da ação, cultivar a atenção e a delicadeza, abrir os olhos e os ouvidos, falar sobre o que nos acontece, aprender a lentidão, escutar os outros, cultivar a arte do encontro, calar muito, ter paciência e dar-se tempo e espaço (Larrosa, 2004, p. 160).

Para Jorge Larrosa (2004, p. 340) "ler como um indivíduo pessoal, costuma jogar contra a liberdade da leitura", 
não permitindo que o inesperado aconteça. A experiência de leitura abordada aqui, ao contrário, é uma prática de liberdade e de abertura. Podemos dizer que esta leitura silenciosa e solitária de literatura nos interessa quando ela se dá como uma leitura de acolhimento, que envolve um risco e a possibilidade de invenção. A leitura se realiza sem objetivo pré-definido. O leitor se entrega, com uma disposição atencional que acolhe tanto o texto quanto as transformações que podem decorrer da leitura. Ele se coloca em perigo ao se afastar das certezas e garantias de um eu constituído e assim poder acessar o plano pré-reflexivo. Como vemos no poema de Rilke, um leitor mergulhando em sua sombra se torna irreconhecível e ao erguer o olhar seus traços estão alterados para sempre.

O leitor

Quem o conhece, a este que baixou seu rosto, de um ser até um segundo ser, a quem apenas o veloz passar das páginas plenas às vezes interrompe com violência?

Nem sequer sua mãe estaria segura se ele é aquele que ali lê algo, mergulhado em sua sombra. E nós, que tínhamos horas, que sabemos de quanto se dissipou

até que, com esforço, ergueu o olhar carregando sobre si o que, abaixo, no livro, acontecia, e com olhos dadivosos, que ao invés de tomar, se topavam com um mundo pleno e pronto:

como crianças caladas que jogavam sozinhas e de pronto vivenciam o existente; mas seus traços, que estavam ordenados, ficaram alterados para sempre. (Rilke, 1908, citado por Larrosa, 1998/2001, p. 97).

A leitura de acolhimento ou à espreita pode levar a esse mergulho na sombra, propiciando a transformação do leitor. Parece haver uma força na leitura literária para provocar uma interrupção na correria que vivemos no dia-a-dia. Percebe-se a leitura como uma forma de resistência ao excesso de informação, como uma parada que pode fazer pensar e levar a um movimento de alterização, a um encontro com a alteridade que existe em nós mesmos. Para que retornemos transformados.

A experiência da leitura pode levar a uma experiência de devir consciente. Natalie Depraz, Francisco Varela e Pierre Vermersch (2003), buscam entender e descrever o que eles chamam de devir consciente, que é o tornar-se ciente de uma experiência, seja ela relativa à história passada ou resultante de um gesto cognitivo realizado no presente. Um processo pelo qual pode surgir na minha consciência alguma coisa de mim mesmo que eu não tinha consciência, pois estava confuso, opaco, afetivo, imanente, pré-refletido. Ressaltam que esta é uma experiência usual, que todos podem ter, mas que muitas vezes não se dão conta. Por isso, buscam desenvolver um meio de cultivar tal habilidade. Esta habilidade de estar presente na própria expe- riência pode ser atingida de muitas formas, entre as quais a meditação budista. Com o objetivo de estudar o ato de devir consciente e, ao mesmo tempo, construir um caminho que permita que todos o alcancem através de um aprendizado, Depraz et al. (2003) aproximam três abordagens de acesso à experiência na primeira pessoa: a introspecção, a fenomenologia e as tradições orientais, como o budismo. A partir daí, descrevem a dinâmica estrutural deste processo pelo qual advém à minha consciência clara alguma coisa que me habitava de modo obscuro, pré-refletido.

A estrutura do ato de devir consciente é constituída por um ciclo básico, que consiste da époché ou redução e evidência intuitiva, além das fases opcionais de expressão e validação. O ciclo básico da redução possui três componentes que são a suspensão, a redireção e o letting-go. Em português não existe uma palavra que seja a tradução literal deste termo. Neste contexto, ele pode ser traduzido como deixar vir. Entretanto, consideramos o termo acolhimento mais apropriado aqui, uma vez que se aproxima da noção de deixar vir e, ao mesmo tempo, remete à disposição de aceitar o que vem, de acolher o que emerge na evidência intuitiva, que está presente neste gesto. A fase de suspensão é a que inicia o processo de devir consciente e algumas vezes precisa ser reativada durante o mesmo. A suspensão refere-se a um gesto de ruptura com relação aos julgamentos habituais que caracterizam a atitude natural. Corresponde a um momento de parada (súbito ou progressivo), de interrupção de um fluxo contínuo, seja de uma ação ou pensamento, que nos impede de ter atenção àquilo que se passa no momento presente. Envolve uma mudança geral de atitude, uma mudança ligada à atenção que a pessoa vai prestar à sua própria experiência e aos outros. A pessoa fica numa posição de observação daquilo que está fazendo. Esta é uma capacidade disponível, mas por não ser mobilizada com freqüência, pode apresentar alguma dificuldade no início. Esta fase funciona como disparadora do ato de devir consciente sendo, portanto, fundamental. É uma disposição global, um tipo de atenção à situação, que precisa ser sempre reativada, retomada, por ser um fio condutor que está presente em todas as etapas.

Redireção diz respeito a uma reversão do funcionamento cognitivo habitual. Há um redirecionamento, uma mudança do sentido da atenção que passa do exterior para o interior. Refere-se a uma dobra sobre si, um voltar a atenção concentrada para si mesmo, ou seja, para a maneira como lidamos com o objeto e não para o objeto mesmo. Este movimento corresponde a um ciclo que conduz de volta a si sem, entretanto, fechar-se em si mesmo, desde que o segundo movimento deste circuito, que é o momento de acolhimento, se dirija para fora, em uma receptividade para si e para o mundo.

A etapa do deixar vir ou acolhimento é, então, uma atividade de receptividade frente à experiência. Aqui a atenção está mais aberta, não focalizada. Este gesto envolve uma mudança na qualidade da atenção, de uma atenção usual que busca, para uma atenção que acolhe. É caracterizado por uma abertura em relação a si mesmo e ao con- 
texto. Trata-se de uma espera passiva, receptiva, com um apagamento transitório da distinção dentro e fora, quando passamos de um buscar para um deixar-vir, deixar revelar-se, deixar operar uma reverberação do vivido (Depraz, Varela, \& Vermersch, 2000). O obstáculo principal a esta terceira fase reside na travessia de um tempo vazio, um tempo de silêncio, uma vez que temos a tendência a preenchê-lo com a realidade imediata.

Estes três gestos são dados ao mesmo tempo ao sujeito, ou seja, aparecem ao mesmo tempo na experiência, estando organicamente ligados. Estas etapas em conjunto permitem a emergência da evidência intuitiva, que se configura como uma descoberta inesperada de algo que não se podia prever, de algo que nos habitava de modo afetivo, mas que não tínhamos conhecimento. Nessa etapa ocorre um encontro com a experiência no seu movimento, no seu acontecer, no que ela possui de experienciar.

As etapas posteriores, de validação e expressão, são etapas opcionais, onde se digere o que aconteceu, pensando ou conversando, e buscando uma preparação para a próxima experiência.

Juntamente com esta estrutura do ato de devir consciente, os autores apresentam exemplos oriundos de diferentes tradições, enfatizando a pluralidade de formas em que o devir consciente pode ser concretizado. A descrição das experiências de devir consciente é feita em primeira pessoa e as práticas escolhidas no livro derivam da vivência pessoal dos autores e de outros pesquisadores associados. A forma de apresentá-los vai variar, uma vez que não há uma formatação rígida de relato, apenas uma estrutura, que é a estrutura do ato de devir consciente. Os exemplos apresentados são: entrevista de explicitação (introspecção guiada), meditação budista (shamatha), visão estereoscópica, sessão de psicanálise, curso de filosofia, escrita e oração. Destes exemplos, podemos apreender que devir consciente é um ato capaz de ser concretizado em uma variedade de formas. São práticas que vêm de diversas tradições e sublinham sua pluralidade. E, ao mesmo tempo, acentuam o caráter absolutamente singular de cada uma destas maneiras de praticar o ato de devir consciente.

Frente às práticas de devir consciente trazidas pelos autores, consideramos que a leitura de literatura também pode ser uma experiência deste tipo. Assim, acrescentamos a seguir uma descrição de uma experiência de leitura silenciosa e solitária de literatura, feita a partir da estrutura do ato de devir consciente apresentada por Depraz et al. (2003).

A leitura literária pode provocar experiências de problematização, estranhamento e invenção de si e do mundo. Tais experiências podem gerar movimentos de produção de subjetividade. Como isso ocorre? Na leitura de um texto, podemos experimentar uma suspensão do que a fenomenologia chama de "atitude natural" - nossa atitude usual de realizar julgamentos acerca do mundo externo. Em suspensão, o leitor direciona sua atenção para a experiência, para o que está ocorrendo no momento. Entregando-se à leitura, pode ocorrer uma surpresa estética, que leva a uma redireção da atenção do exterior para o interior, desencadeando uma relação consigo mesmo que não é reflexiva, que não pertence à dimensão recognitiva. Após a leitura, ou mesmo em interrupções que podem ocorrer durante a própria leitura, coloca-se a necessidade de um tempo vazio. Nessa espera, há uma mudança na qualidade da atenção que passa de uma atenção que busca para uma atenção que acolhe. Se o leitor conseguir sustentar esse vazio sem preenchê-lo, permitindo que o texto ressoe nele, poderá ocorrer a evidência intuitiva, que completa a experiência de devir consciente. $\mathrm{O}$ acesso ao plano pré-reflexivo e a emergência de algo que nos habitava, mas que não tínhamos conhecimento e que, por isso, pode nos surpreender.

Depraz et al. (2003) consideram que a experiência de devir consciente envolve diversas fases. Estas serão exploradas com mais detalhes em seguida, especificamente em relação à experiência de leitura.

\section{Preliminares: Objetivos, Preparação e Tempo da Leitura}

Os objetivos da leitura podem variar bastante, indo desde a aquisição de informação, passando pelo estudo, a obrigação, o prazer e a fruição. Mas na modalidade focalizada aqui, ela não possui um fim pré-determinado, a não ser a própria leitura. Mesmo que se inicie uma leitura com um propósito exterior ao próprio ato de ler, ele pode modificar-se no seu decorrer. Os efeitos da leitura não podem ser previstos antecipadamente.

A posição corporal básica é estar sentado ou deitado, solitário, em silêncio e com o livro ao alcance dos olhos. Um local agradável e tranqüilo é preferível, mas pode-se ler em qualquer lugar. Essa experiência de leitura pressupõe uma disponibilidade de tempo e um certo estado de relaxamento, de entrega e de atenção.

O tempo de duração da atividade e sua periodicidade são variáveis, mas devem ser suficientes para que uma verdadeira relação com o texto ocorra. Cada experiência de leitura possui um tempo próprio. De acordo com o ritmo que se estabelece, a leitura pode transcorrer de forma acelerada, quando devoramos o livro e muitas vezes não queremos interromper a leitura até seu ponto final. Em outras ocasiões lemos vagarosamente, saboreando, relendo, pensando, interrompendo a leitura de tempos em tempos, quase que economizando para que não terminemos o livro tão cedo.

\section{Suspensão e Redireção}

Uma atitude geral de suspensão pode ocorrer na medida em que há um afastamento do mundo externo, uma interrupção de um fluxo contínuo, quando abandonamos outras atividades para nos dedicar à leitura. Mergulhando na leitura deixamos de lado as atitudes e julgamentos habituais, permitindo que nossa atenção se volte para o texto. Com essa atenção aberta e concentrada o leitor pode estabelecer uma relação intensa com o texto, deixando-se levar por ele. Essa atitude de suspensão, porém, é precária, podendo ser perdida ao longo da leitura. Por isso, algumas vezes 
precisa ser reiniciada. A leitura exige, portanto, uma atenção concentrada, para que os estímulos do ambiente não fragmentem ou interfiram na leitura. Porém, quando estamos atentos e entregues à leitura, muitas vezes nos concentramos de tal forma que não vemos ou ouvimos mais nada do que se passa ao redor.

Nesse contato com o texto, podemos vivenciar uma surpresa estética, que envolve uma quebra na recognição, uma experiência de breakdown (Varela, 1995). Essa experiência de estranhamento consolida a atitude suspensiva, levando a uma redireção da atenção, que se desloca do exterior para o interior (redireção). Nos momentos em que levantamos os olhos da página, ou durante os intervalos de leitura, ou mesmo algum tempo depois que paramos de ler, a atenção se dirige para o próprio leitor, ocorrendo uma dobra sobre si. Esta, entretanto, é uma relação consigo mesmo que não é uma relação reflexiva, mas ocasião em que se entra em contato com o plano da virtualidade de si, o plano pré-reflexivo.

\section{Acolhimento}

Esse gesto envolve um tempo de espera, um tempo de abertura, onde se sustenta um vazio. Há uma mudança na qualidade da atenção, de uma atenção que busca para uma atenção que acolhe. Diz respeito a uma atitude de estar presente na experiência, uma prática de atenção e presença a si e ao contexto. Neste momento o leitor encontra-se passivo e receptivo frente à experiência, à espera de um evento cujo conteúdo ainda não está claro. É necessário que se respeite o vazio, a espera, mantendo uma abertura para si mesmo e para o mundo, em uma disposição de aceitação, receptividade e acolhimento. O que foi lido reverbera. Percebe-se que efeitos poderão emergir, mas não se sabe quais.

\section{Evidência Intuitiva}

Essas etapas em conjunto permitem a emergência da evidência intuitiva, onde algo que nos habitava, mas de que não tínhamos ciência, emerge. Experiências não conscientes tornam-se conscientes e claras. E, muitas vezes, o que emerge causa estranhamento, colocando o leitor em contato com a alteridade que o habita. Pode ser um problema que se coloca ou algo insuspeitável que, subitamente, passa a fazer sentido. A emergência de uma novidade quebra a continuidade da experiência e da visão de mundo do leitor. Mudanças se processam em tempos variáveis. Podem ser grandes rupturas ou pequenas fragmentações. E o leitor não é mais o mesmo. Conforme Kastrup (2003), a prática de devir-consciente revela-se como uma prática de si, uma prática de transformação de si e de produção de subjetividade.

Entretanto, não há certeza de que a evidência intuitiva vá ocorrer. Ela existe, enquanto possibilidade, em qualquer prática de devir consciente. Mas algumas vezes ela vai se dar, outras vezes não. Não existe garantia, nem fórmulas para que essa emergência do desconhecido possa acontecer.

\section{Expressão, Validação e Efeitos Posteriores}

Podemos marcar o texto, fazer anotações, escrever, conversar com alguém sobre o que foi lido. A experiência de leitura literária é algo capaz de permanecer em nós e continuar a produzir efeitos. Esses efeitos podem emergir durante a leitura ou muito tempo depois dela ter sido concluída. Seus efeitos demandam um tempo de ressonância (Caiafa, 2000), um tempo de ruminação (Schopenhauer, s.d.), um tempo que se perde. Além disso, não se pode prever quais serão esses efeitos. Por isso, a experiência da leitura envolve riscos. Não sabemos que movimentos ou transformações as ressonâncias do texto lido podem provocar.

Um ponto importante que merece ser destacado em relação ao devir consciente diz respeito à peculiaridade de seu aprendizado, uma vez que se trata de um aprender fazendo (Depraz et al., 2003). A evidência intuitiva só pode ser experienciada a partir de uma prática encarnada, em alguma ação efetiva. A leitura de acolhimento só pode ser alcançada pela própria leitura. A capacidade de entregar-se à experiência de leitura somente pode ser cultivada com a prática. Além disso, é um tipo de aprendizado que nunca está garantido. Nesta perspectiva, saber fazer algo ou fazê-lo bem depende de um praticar contínuo. Não é um saber que se adquire de uma vez por todas e que está assegurado enquanto um conhecimento ou uma habilidade que se possui. Tem a natureza de um cultivo, necessitando de trabalho e de prática constante. Sem o fazer o saber se esvai, se perde e somente pode ser recuperado com esforço e persistência. Como relata o escritor Varlam Chalámov, que viu sua prática de leitura ser interrompida por pelo menos cinco anos devido à sua prisão na Rússia. Ele relata:

Eu abri o volume, endireitando suas páginas com as duas mãos, bati os olhos no texto e logo percebi que havia perdido minha antiga capacidade de leitura . . . naquele momento, eu fitava o texto e não assimilava nada. Ainda havia claridade suficiente, e eu comecei a ler em voz alta, sussurrando palavra por palavra, sem sentir nenhum prazer naquilo. Os livros não eram mais meus companheiros; eu havia me desacostumado a eles, e eles a mim. Fiquei perturbado com o fato, mas com alguma força de vontade me obriguei a seguir lendo. Minha cabeça doía, quase explodindo de tanto esforço, mas pouco a pouco consegui me envolver na leitura (Chalámov, 2004, p. 87).

Num certo sentido, a leitura precisa de um costume, de uma regularidade, e do desenvolvimento de uma certa capacidade apreciativa, configurando uma inclinação e um desejo. Esses constituem uma maneira de ser e de viver.

A atitude em relação à leitura e à literatura - tanto no tocante ao costume de praticá-las quanto no que concerne ao valor que lhe é atribuído, ambos gerados no processo de aprendizagem inventiva - diz respeito a uma certa relação da cognição com o presente, em sua condição de abertura dos limites da história (Kastrup, 2002, p. 91). 
Larrosa (1998/2001) fala de uma modalidade de escrita, exemplificada pelo texto de Peter Handke, que teria a capacidade de criar silêncios. Um texto que despersonaliza a linguagem e transmite silêncios. Essa modalidade de escrita permite um tipo de leitura que, na descrição de Larrosa, parece um ato de devir consciente. Primeiro ele fala que esta escrita silencia o convencional e produz no leitor um calar e um estar voltado para si mesmo. O que podemos considerar como uma suspensão da atitude natural e redireção da atenção do exterior para si mesmo. Ele diz ainda que o silêncio que essa escrita transmite é feito de escuta e de recolhimento, remetendo à idéia de acolhimento, de abertura e deixar vir, presentes no ato de devir consciente. Por último, para ele o contato com o texto provocaria uma surpresa estética que levaria a um desprendimento de nós mesmos e, ao mesmo tempo, a uma máxima intimidade conosco. Caracterizaria então um tipo de relação consigo mesmo propiciada pela emergência da evidência intuitiva, um contato consigo que seria abertura e alterização.

Podemos dizer que para que o devir consciente possa se dar na leitura é necessário que o texto seja propício a produzir silêncios e que a leitura não tenha outro objetivo que não ela mesma. Que o leitor disponha de tempo e que se permita uma disposição de entrega e abertura aos movimentos do texto.

\section{Referências}

Adams, M. J. (1990). Beginning to read: Learning and thinking about print. Cambridge, MA: MIT Press.

Barrera, S. D., \& Maluf, M. R. (2004). Variação lingüística e alfabetização: Um estudo com crianças da primeira série do ensino fundamental. Psicologia Escolar e Educacional, 8, 35-46.

Caiafa, J. (2000). Nosso século XXI: Notas sobre arte, técnicas e poderes. Rio de Janeiro, RJ: Relume Dumará.

Capovilla, A. G. S. (2002). Leitura e escrita como fatores de inclusão: Comparando a eficácia dos métodos fônico e global de alfabetização. Revista Psicopedagogia, 19, 4-24.

Capovilla, A. G. S. (2003). Alfabetização. Revista Acadêmica Augusto Guzzo, 6, 10-13.

Capovilla, A. G. S., \& Capovilla, F. C. (2002). Otimizando a aquisição da linguagem escrita: Comparação entre métodos de alfabetização. Cadernos de Psicopedagogia, 2, 70-103.

Chalámov, V. (2004). Minhas bibliotecas. In J. Silveira \& M. Ribas (Eds.), A paixão pelos livros (pp.75-104). Rio de Janeiro, RJ: Casa da Palavra.

Chartier, R. (1998). A aventura do livro: Do leitor ao navegador. São Paulo, SP: Editora da Universidade Estadual Paulista "Júlio de Mesquita Filho".

Chartier, R. (1999). A ordem dos livros: Leitores, autores e bibliotecas na Europa entre os Séculos XIV e XVIII. Brasília, DF: Editora da Universidade de Brasília.

Chartier, R. (2003). Formas e sentido: Cultura escrita: Entre distinção e apropriação. Campinas, SP: Mercado de Letras. (Original publicado em 1995)

Correa, J., \& MacLean, M. (1999). Aprendendo a ler e a escrever: A narrativa das crianças sobre a alfabetização. Psicologia: Reflexão e Crítica, 12, 273-286.
Depraz, N., Varela, F. J., \& Vermersch, P. (2000). La réduction à l'épreuve de l'expérience. Études Phénoménologiques, 31-32, 165-184.

Depraz, N., Varela, F. J., \& Vermersch, P. (2003). On becoming aware: A pragmatics of experiencing. Philadelphia, PA: John Benjamins.

Ferrand, L. (2001). Cognition et lecture: processus de base de la reconnaissance des mots écrits chez l'adulte. Ouvertures psychologiques. Bruxelles, Belgique: Éditions De Boeck Université.

Ferreira, S. P. A., \& Dias, M. G. B. B. (2004). A leitura, a produção de sentidos e o processo inferencial. Psicologia em Estudo, 9, 439-448.

Fontes, M. J. O., \& Cardoso-Martins, C. (2004). Efeitos da leitura de histórias no desenvolvimento da linguagem de crianças de baixo nível sócio-econômico. Psicologia: Reflexão $e$ Crítica, 17, 83-94.

Gonçalves, F., \& Dias, M. G. B. B. (2003). Coerência textual: Um estudo com jovens e adultos. Psicologia: Reflexão e Crítica, 16, 29-40.

Kastrup, V. (1999). A invenção de si e do mundo: Uma introdução do tempo e do coletivo no estudo da cognição. Campinas, SP: Papirus.

Kastrup, V. (2002). Cartografias literárias. Revista do Departamento de Psicologia - UFF, 14, 75-94.

Kastrup, V. (2003). Production de subjectivité dans un atelier de lecture au Brésil. Chimères, 49, 95-110.

Larrosa, J. (2001). Pedagogia profana: Danças, piruetas e mascaradas. Belo Horizonte, MG: Antêntica. (Original publicado em 1998)

Larrosa, J. (2002). Notas sobre a experiência e o saber da experiência. Revista Brasileira de Educação, 19, 20-28.

Larrosa, J. (2003). La experiencia de la lectura. México, DF: Fondo de Cultura Económica. (Original publicado em 1996)

Larrosa, J. (2004). Linguagem e educação depois de Babel. Belo Horizonte, MG: Autêntica.

Mackey, M. (2003). Researching new forms of literacy. Reading Research Quarterly, 3, 403-407.

Maia, A. C. B., \& Fonseca, M. L. (2002). Quociente de inteligência e aquisição de leitura: Um estudo correlacional. Psicologia: Reflexão e Crítica, 15, 261-270.

Maluf, M. R., \& Barrera, S. D. (2004). Variação lingüística e alfabetização. Psicologia Escolar e Educacional, 8, 35-46.

Medeiros, J. G., \& Silva, R. M. F. (2002). Efeitos de testes de leitura sobre a generalização em crianças em processo de alfabetização. Psicologia: Reflexão e Crítica, 15, 587-602.

Medeiros, J. G., Fernandes, A. R., Pimentel, R., \& Simone, A. C. S. (2004). A função da nomeação oral sobre comportamentos emergentes de leitura e escrita ensinados por computador. Estudos de Psicologia (Natal), 9, 249-258.

Morais, J. (1996). A arte de ler. São Paulo, SP: Editora da Universidade Estadual Paulista "Júlio de Mesquita Filho".

Oliveira, J. B. A. (2005). Avaliação em alfabetização. Ensaio, Avaliação e Políticas Públicas em Educação, 13, 375-382.

Proust, M. (1956). Em busca do tempo perdido. No caminho de Swann. Porto Alegre, RS: Globo. (Original publicado em 1948)

Rego, L. L. B. (1995). Diferenças individuais na aprendizagem inicial da leitura: Papel desempenhado por fatores metalingüísticos. Psicologia: Teoria e Pesquisa, 11, 51-60.

Sawaya, S. M. (2000). Alfabetização e fracasso escolar: Problematizando alguns pressupostos da concepção construtivista. Educação e Pesquisa, 26, 67-81.

Schopenhauer, A. (s.d.). Sobre livros e leitura. Porto Alegre, RS: Paraula. 
Sousa, E. O., \& Maluf, M. R. (2005). Habilidades de leitura e de escrita no início da escolarização. Psicologia da Educação, 19, 55-72.

Sprenger-Charolles, L., \& Casalis, S. (1996). Lire. Lecture et écriture: acquisition et troubles du développement. Paris: PUF.

Varela, F. J. (1995). Sobre a competência ética. Lisboa, Portugal: Edições 70.

Varela, F. J., Thompson, E., \& Rosch, E. (2003). A mente incorporada: Ciências cognitivas e experiência humana. Porto Alegre, RS: Artmed. (Original publicado em 1991)

Veloso, C. (2004). Livros. In J. Silveira \& M. Ribas (Eds.), A paixão pelos livros (pp. 49-50). Rio de Janeiro, RJ: Casa da Palavra.

Witter, G. P. (2000). Como ajudar a criança com a escrita e a leitura. Psicologia Escolar e Educacional, 4, 44-79.

Witter, G. P. (2003). Leitura: Estratégias de aprendizagem de vocábulos. Revista do Unipê, 7, 78-92.

Zanella, M. S., \& Maluf, M. R. (2004). Contraponto entre a leitura e a escrita de crianças durante os primeiros anos de aprendizagem escolar. Psicologia da Educação, 18, 55-75. 